\title{
Endovascular management of acute epidural hematomas: clinical experience with 80 cases
}

\author{
Carlos Michel A. Peres, MD, ${ }^{1}$ Jose Guilherme M. P. Caldas, MD, PhD, ${ }^{2}$ Paulo Puglia Jr., MD, ${ }^{2}$ \\ Almir F. de Andrade, MD, PhD, ${ }^{3}$ Igor A. F. da Silva, MD, ${ }^{3}$ Manoel J. Teixeira, MD, PhD, ${ }^{3}$ and \\ Eberval G. Figueiredo, MD, $\mathrm{PhD}^{3}$
}

${ }^{1}$ Hospital Universitário Francisca Mendes, Manaus; and Divisions of ${ }^{2}$ Neuroradiology and ${ }^{3}$ Neurosurgery, University of São Paulo School of Medicine, São Paulo, Brazil

OBJECTIVE Small acute epidural hematomas (EDHs) treated conservatively carry a nonmeasurable risk of late enlargement due to middle meningeal artery (MMA) lesions. Patients with EDHs need to stay hospitalized for several days, with neurological supervision and repeated CT scans. In this study, the authors analyzed the safety and efficacy of the embolization of the involved MMA and associated lesions.

METHODS The study group consisted of 80 consecutive patients harboring small- to medium-sized EDHs treated by MMA embolization between January 2010 and December 2014. A literature review cohort was used as a control group.

RESULTS The causes of head injury were falls, traffic-related accidents (including car, motorcycle, and pedestrian vs vehicle accidents), and assaults. The EDH topography was mainly temporal (lateral or pole). Active contrast leaking from the MMA was seen in 57.5\%; arteriovenous fistulas between the MMA and diploic veins were seen in 10\%; and MMA pseudoaneurysms were found in $13.6 \%$ of the cases. Embolizations were performed under local anesthesia in $80 \%$ of the cases, with $\mathrm{N}$-butyl-2-cyanoacrylate, polyvinyl alcohol particles, or gelatin sponge (or a combination of these), obtaining MMA occlusion and complete resolution of the vascular lesions. All patients underwent follow-up CT scans between 1 and 7 days after the embolization. In the 80 cases in this series, no increase in size of the EDH was observed and the clinical evolution was uneventful, without Glasgow Coma Scale score modification after embolization and with no need for surgical evacuation. In contrast, the control cohort from the literature consisted of 471 patients, $82(17.4 \%)$ of whom shifted from conservative treatment to surgical evacuation.

CONCLUSIONS This study suggests that MMA embolization is a highly effective and safe method to achieve size stabilization in nonsurgically treated acute EDHs.

https://thejns.org/doi/abs/10.3171/2016.11.JNS161398

KEY WORDS epidural hematoma; traumatic brain injury; middle meningeal artery; pseudoaneurysm; embolization; endovascular treatment; vascular disorders

A CUTE epidural hematoma (EDH) is one of the most dramatic and urgent traumatic brain injuries (TBIs). Patients frequently present with sudden neurological deterioration. In these cases, the most common cause is a tearing of the middle meningeal artery (MMA) near the foramen spinosum. In such circumstances, rapid clinical deterioration requires prompt surgical evacuation before the onset of brain dysfunction. ${ }^{4}$

Small EDHs have not been adequately studied thus far, and their incidence, natural history, clinical relevance, and ideal management remains to be well established. 5,7,27 However, late enlargement of previously small hematomas is a well-recognized clinical occurrence. ${ }^{25}$ One of the most hazardous events in the rupture of intracranial vessels is the relatively slow but continuous expansion of the hematoma and sudden neurological deterioration. Traditionally, these patients need to stay in the hospital for several days or weeks under conservative management, including close neurological supervision and several repeated CT scans. ${ }^{9}$

Recently, endovascular management of intracranial

ABBREVIATIONS AVF = arteriovenous fistula; EDH = epidural hematoma; GCS = Glasgow Coma Scale; MMA = middle meningeal artery; NBCA = N-butyl-2-cyanoacrylate; OphA = ophthalmic artery; $\mathrm{PVA}$ = polyvinyl alcohol; $\mathrm{SAH}$ = subarachnoid hemorrhage; $\mathrm{SDH}$ = subdural hematoma; $\mathrm{TBI}$ = traumatic brain injury.

SUBMITTED May 31, 2016. ACCEPTED November 7, 2016.

INCLUDE WHEN CITING Published online April 14, 2017; DOI: 10.3171/2016.11.JNS161398. 
vascular lesions associated with small EDHs has been proposed as a safe and effective treatment option. ${ }^{6,20,24,28}$ In this paper, we describe our experience with the endovascular management of EDHs in 80 consecutive patients (thus far the largest reported series to the best of our knowledge), and compare it with historical cohorts.

\section{Methods \\ Patient Population}

This study included all patients with traumatic EDH consecutively admitted to the Neurotrauma Department of the Hospital das Clínicas da Universidade de São Paulo between January 2010 and December 2014, for whom conservative management was chosen based on standard criteria. ${ }^{4}$ The institutional review board approved the study protocol and all patients provided written informed consent.

We excluded patients who had large hematomas, midline shift, depressed skull fractures, or other injuries related to the EDH; patients without complete imaging studies at the onset (such as those acquired at another institution); patients with coagulopathy; and those without complete clinical data.

\section{Control Group}

A historical control group composed of cohorts of patients with small EDHs was used, after a systematic review in the MEDLINE database of papers published between 1986 and 2016. Eligibility criteria included cohort studies of late expansion of previously small EDHs resulting in surgical procedures for evacuation. Only complete text articles written in English were evaluated.

\section{Information Sources}

The MEDLINE database and Google Scholar were searched for papers that met the inclusion criteria. An unpublished data quest and a gray search were additionally performed.

The first search in the MEDLINE database was performed as follows: two searches were carried out, one for end-point terms and the other for the patients in the MEDLINE database. These terms were selected by 3 different authors (C.M.A.P., E.G.F., J.G.M.P.C.). Both searches were then additionally matched using the term AND.

\section{Study Selection and Data Collection Process}

All the abstracts were analyzed by 3 independent reviewers (C.M.A.P., E.G.F., J.G.M.P.C.). Cohorts were included if they met the eligibility criteria, and the full text version was analyzed. Only patients with the evaluated outcomes (expansion of small EDHs) were included in the final analysis.

\section{Endovascular Procedures}

Under local (80\% of patients) or general (20\% of patients) anesthesia, a femoral sheath was introduced and a 6-Fr guiding catheter was inserted into the external carotid artery on the lesion side. An angiographic study was performed, followed by superselective angiography of the
MMA with a microcatheter, followed by gentle injection of iodine contrast. Careful attention was paid to detect the choroidal blush caused by anastomotic vessels supplying the ophthalmic artery (OphA) via the superior orbital fissure or foramen of Hyrtl and the petrosal branch of the MMA to the territory of the facial nerve.

The microcatheter was then advanced as far as possible in the MMA, stopping just before identifiable contrast extravasation, pseudoaneurysms, arteriovenous fistulas (AVFs), or visible arterial tearing. Next, embolization of the MMA was performed with $20 \% \mathrm{~N}$-butyl-2-cyanocrylate (NBCA), polyvinyl alcohol (PVA) particles of 250-350 $\mu \mathrm{m}$ or 300-500 $\mu \mathrm{m}$, gelatin sponge (Gelfoam), or a combination of the 3 , until a cessation of the contrast material leakage or stopping of the parent vessel (distal MMA) flow had been observed, or microcatheter reflux occurred. In cases of pseudoaneurysms, the proximal segment, the lumen, and the distal segment were occluded with NBCA (Fig. 1).

After the withdrawal of the microcatheter, an angiographic follow-up series, performed through the guiding catheter, showed complete resolution of the vascular lesion in all but 3 cases. In these cases, a new microcatheter was then used until complete occlusion of any additional abnormal MMA branch occurred.

\section{Results}

In the period of the study, 80 patients were treated conservatively and were included. Seventy-two patients were male and 8 were female (age range 12-72 years; mean age 39.8 years, median age 38 years). All patients had small EDHs in regions corresponding to bleeding from branches of the MMA. Most of the patients (76.25\%) presented with a score of 14 or 15 on the Glasgow Coma Scale (GCS) on admission (Table 1). No neurological deficits related to the EDHs were observed.

The causes of head injury were mainly falls, traffic-related accidents (including car, motorcycle, and pedestrian vs vehicle accidents), and assaults (Table 2). Cranial fractures were present in $78.7 \%$ of the patients. Other associated intracranial injuries seen on CT scans are summarized in Table 3. Fifty-seven (71.25\%) of the EDHs were located in the temporal region. The mean distance from the foramen spinosum (recognized by the sharp turn of the MMA along the floor of the middle cranial fossa) and the hematoma was $38 \mathrm{~mm}$. Forty-one $(51.2 \%)$ were on the left side. The average thickness was $8.65 \mathrm{~mm}$ in the lateral temporal region, and it reached $10.5 \mathrm{~mm}$ in the temporal pole. Some of the patients in our series had previously undergone urgent craniotomy for contralateral lesions. The presence of contralateral hematoma, controlled with embolization, was also considered in these cases (Fig. 2).

The most frequent site of EDH was the temporal pole or middle cranial fossa. The distal branches of the MMA can rupture and cause hematomas in the frontal or parietal areas. Real-time bleeding may be identified as contrast extravasation on the angiogram (Fig. 3). ${ }^{9,15}$

Angiographic findings are summarized in Table 4. The active contrast leaking from the MMA was the most important finding. It was the only feature in 46 patients 


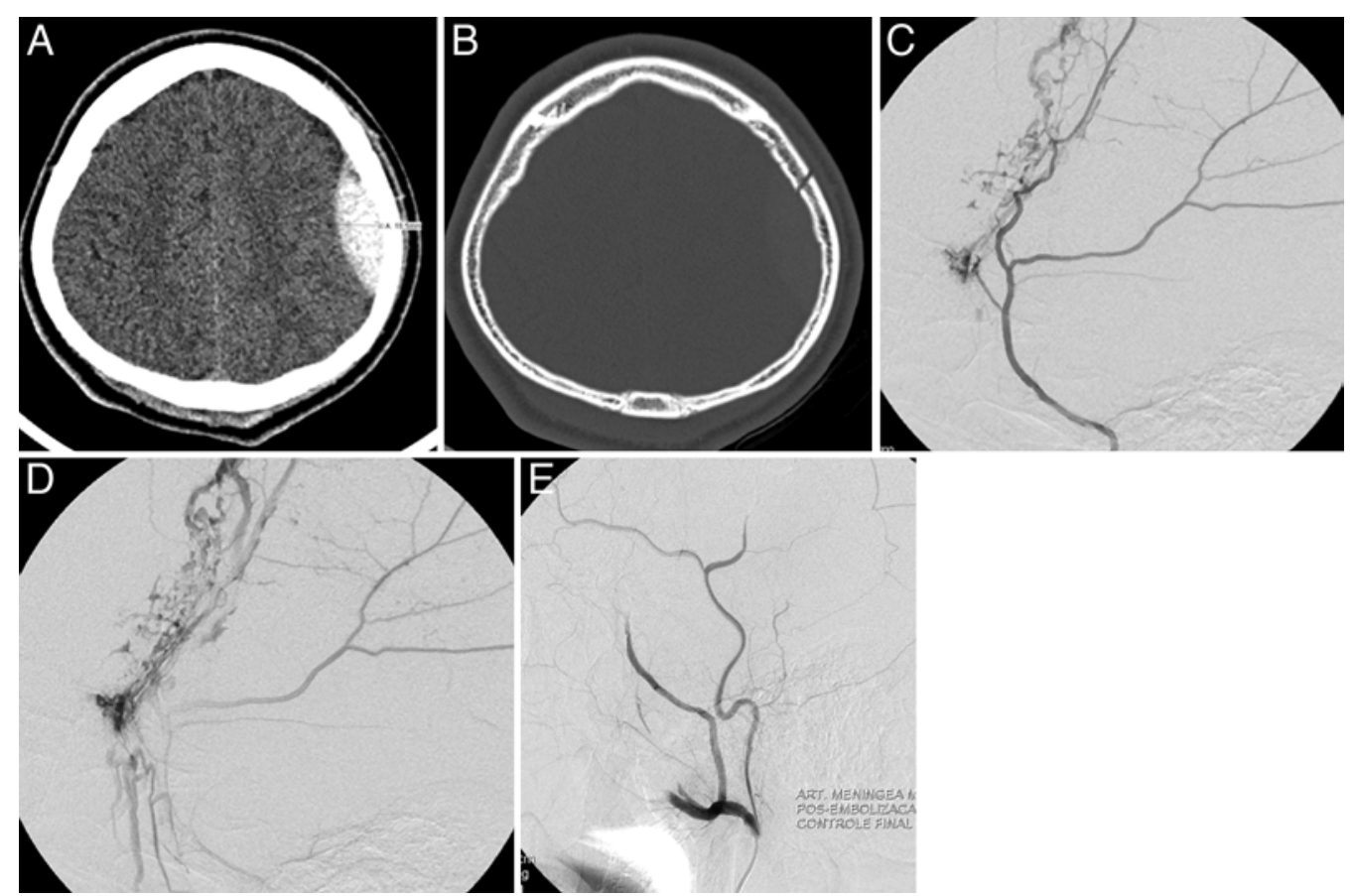

FIG. 1. Axial CT images of EDH with related fracture (A and B), and angiographic studies showing active contrast extravasation (C) and AVF (D-note the diploic vein). Angiographic view after embolization (E), with resolution of both AVF and contrast extravasation.

(57.5\%), but it was also found to be associated with most of the other lesions (as with pseudoaneurysms and AVFs). An AVF was seen on angiographic images in 8 patients (10\%), manifesting as early filling of diploic veins juxtaposed to the MMA. Pseudoaneurysms of the MMA were seen in $13.6 \%$ (Fig. 4).

Embolizations were performed with PVA particles and Gelfoam in 60 patients (75\%). In 17 patients (21.2\%), PVA alone was used. Combined microcoils, NBCA, and Gelfoam were used in 3 patients. All patients had follow-up CT scans between 1 and 7 days after the embolization. In the 80 cases in our study, no increase in size of the EDH was observed. The clinical evolution of the 80 cases was uneventful, without modification in GCS scores after embolization. Outpatient clinical data and follow-up CT

TABLE 1. Summary of clinical data in 80 patients with EDH

\begin{tabular}{lcr}
\hline \multicolumn{1}{c}{ Features } & Value & $\%$ \\
\hline GCS score on admission & & \\
\hline $14-15$ & 61 & 76.2 \\
\hline $12-13$ & 10 & 12.5 \\
\hline$\leq 11$ & 9 & 11.2 \\
\hline Total & 80 & 100.0 \\
\hline Hospitalization duration (days) & & \\
\hline Median & 7 & \\
\hline Mean & 10.5 & \\
\hline Admission to femoral puncture (days) & & \\
\hline Median & 4 & \\
\hline Mean & 4.6 \\
\hline
\end{tabular}

scans obtained between 1 and 3 months were available in 76 patients, all of them without any clinical or radiological deterioration.

Our literature-based control cohort consisted of a total of 471 patients, 82 (17.4\%) of whom were shifted to surgical evacuation. Given that the odds ratio is the ratio of the odds of surgical evacuation indication after embolization divided by the odds with the control group (literature cohort of conservatively treated patients), it was impossible to calculate it because the former value was zero. Table 5 summarizes the control cohort, which includes the larger published series of patients with conservatively managed EDH. ${ }^{1,2,5,11,12,14,19,27}$

\section{Discussion}

Patients with an EDH volume of more than $30 \mathrm{ml}$, thickness of more than $15 \mathrm{~mm}$, a midline shift greater than

TABLE 2. Causes of head injury in 80 patients with EDH

\begin{tabular}{lcc}
\hline Trauma Mechanism & No. & $\%$ \\
\hline Fall & 26 & 32.5 \\
\hline Vehicle vs pedestrian & 15 & 18.7 \\
\hline Car accidents & 12 & 15.0 \\
\hline Motorcycle accidents & 9 & 11.2 \\
\hline Assault & 9 & 11.2 \\
\hline Other/unknown & 9 & 11.2 \\
\hline Total & 80 & 100.0 \\
\hline
\end{tabular}

* Buried alive by landslide or trench collapse, cranial collisions while playing football. 
TABLE 3. Cranial lesions and topography in 80 patients with EDH

\begin{tabular}{cc}
\hline CT Findings & Value (\%) \\
\hline Associated lesions & $63(78.75)$ \\
\hline Fracture & $7(8.75)$ \\
\hline Contusion \& fracture & $4(5.0)$ \\
\hline Fracture \& tSAH & $1(1.2)$ \\
\hline Contusion \& tSAH & $1(1.2)$ \\
\hline Contusion & $1(1.2)$ \\
\hline Pneumocephalus & $3(3.7)$ \\
\hline No associated lesions & \\
\hline EDH topography & $29(36.2)$ \\
\hline Temporal-lateral & $28(35.0)$ \\
\hline Temporal pole & $11(13.7)$ \\
\hline Frontal & $9(11.2)$ \\
\hline Parietal & $3(3.7)$ \\
\hline Frontotemporal &
\end{tabular}

$\mathrm{tSAH}=$ traumatic $\mathrm{SAH}$

$5 \mathrm{~mm}$, or clinical deterioration are the usual candidates for surgical treatment. ${ }^{4}$

The role of nonoperative treatment of acute EDHs is still not well established in neurosurgical practice. However, patients who present in good clinical condition, without deterioration in GCS score, pupillary dilation, or focal neurological deficits, and who harbor EDHs with no compressive effects generally remain under close neurological observation and undergo repeated CT scans. These patients should be admitted to the intensive care unit and monitored for changes in neurological status and vital signs..$^{14}$ This routine, although completely justifiable, raises considerably the economic costs and radiation exposure and carries a nonmeasured risk of sudden neurological decompensation.

There is no consensus in the literature regarding the required length of expectant management. In a series of 252 consecutive patients with traumatic EDH in which 160 patients were initially treated conservatively, enlargement of the hematoma occurred in 37 patients (23\%), with a mean enlargement of $7 \mathrm{~mm}$ and a mean time to enlargement of 8 hours after the trauma. ${ }^{27}$ In another series, $64.9 \%$ of the

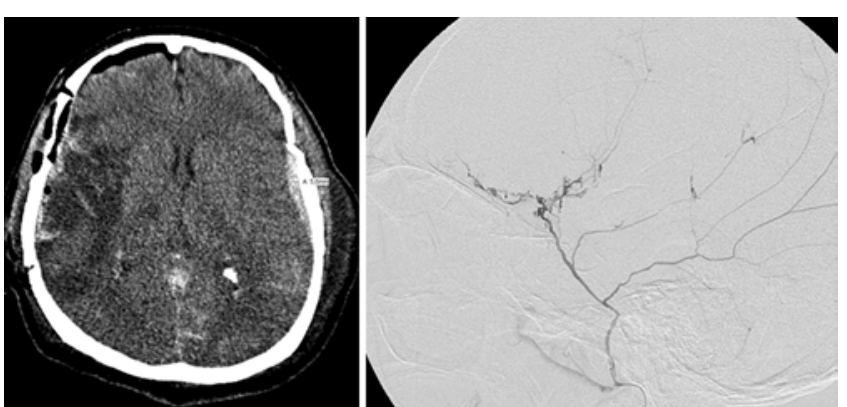

FIG. 2. Left: Axial CT showing bilateral trauma, surgically treated on the right side, with laminar EDH on the left side. Right: Angiogram obtained with microcatheterization of the MMA showing acute contrast extravasation related to the left-sided EDH.

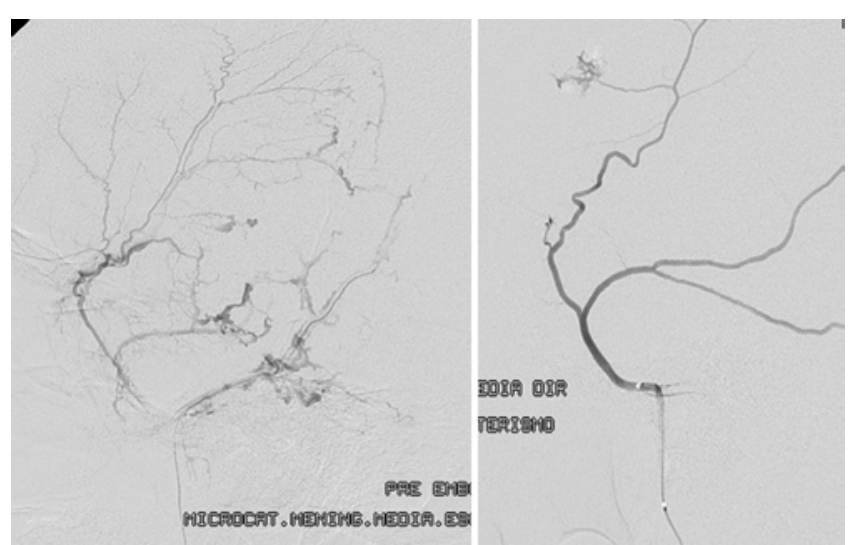

FIG. 3. Angiograms obtained with microcatheterization of the MMA showing contrast extravasation in 2 cases.

patients had enlargement of their EDHs..$^{25}$ Enlargement of an EDH does not necessarily indicate surgery; nonetheless, in a prospective study of patients who had a small EDH diagnosed within 24 hours of trauma and whose injuries were managed expectantly, $32 \%$ subsequently required craniotomy for evacuation of the hematoma within 1-10 days after the trauma. ${ }^{14}$ In another series of 125 patients with EDH treated conservatively, $11.2 \%$ required delayed surgery. ${ }^{2}$

Although the deterioration can be the result of progressive brain swelling and ischemia, rebleeding or continued hemorrhage remains a concern in nonoperative management. In our series, we demonstrated that this issue may be reduced or even eliminated with endovascular embolization. Laboratory investigations with electron microscopy have shown that the dura mater has 5 layers. The MMA runs in the vascular layer of the dura, which is covered outside by the outer dural border layer, which is $2 \mu \mathrm{m}$ thick, and inside by the dural border cell layer, which is 8 $\mu \mathrm{m}$ thick. ${ }^{23}$ This may be the reason why the most common presentation of tearing of the MMA is bleeding into the epidural space caused by a skull fracture, resulting in the separation of dura mater and bone. Acceleration-induced shear may explain the occurrence of EDH without visible skull fracture. Nevertheless, it is possible to find subdu-

TABLE 4. Angiographic findings in 80 patients with EDH

\begin{tabular}{lc}
\hline \multicolumn{1}{c}{ Angiographic Finding } & Value (\%) \\
\hline Active contrast extravasation & $46(57.5)$ \\
\hline MMA wall irregularities & $8(10.0)$ \\
\hline Acute contrast extravasation \& pseudoaneurysm & $7(8.7)$ \\
\hline Acute contrast extravasation \& AVF & $5(6.2)$ \\
\hline Pseudoaneurysm & $3(3.7)$ \\
\hline AVF & $2(2.5)$ \\
\hline Pseudoaneurysm \& AVF & $1(1.2)$ \\
\hline Choroidal blush & $1(1.2)$ \\
\hline MMA wall irregularities \& ICA aneurysm & $1(1.2)$ \\
\hline Normal & $6(7.5)$ \\
\hline Total & 80 \\
\hline
\end{tabular}

ICA = internal carotid artery 


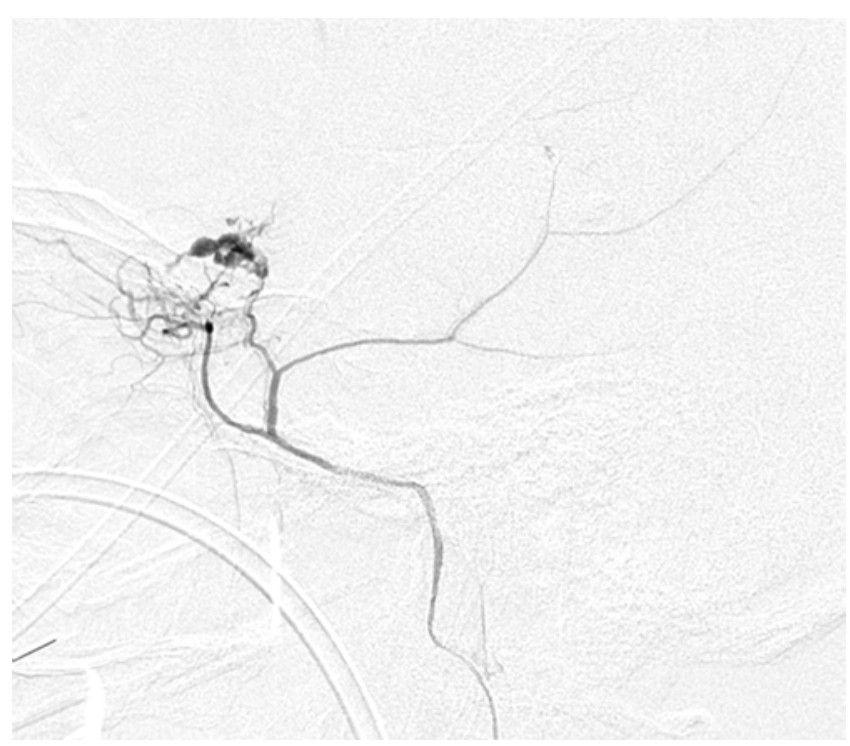

FIG. 4. Angiogram showing MMA pseudoaneurysm.

ral hematomas (SDHs) or even subarachnoid hemorrhage (SAH) and intracerebral hematomas. ${ }^{22,32}$

Rupture of the MMA may lead to the formation of traumatic aneurysms, most of them believed to be pseudoaneurysms, whose walls are histologically composed of fibrous connective tissue of the surrounding anatomical structures. Normal arterial layers are absent in these instances. ${ }^{3}$ Angiographically, these "false" aneurysms usually fill late in the arterial phase, opacify less, and empty more slowly than saccular aneurysms. "True" aneurysms do occur in the MMA, with the same histological characteristics as aneurysms of cerebral arteries, both in the context of trauma and in diseases that put increased hemodynamic stress on the wall of the artery, such as Paget's disease, dural arteriovenous malformations, moyamoya disease, and meningiomas. ${ }^{18}$

Pseudoaneurysms of the MMA, although rare, may produce abrupt neurological deterioration due to rapid enlargement of an $\mathrm{EDH}$, after a 3- to 30-day interval. ${ }^{14,30}$ Nowadays, these vascular lesions may be missed due to the widespread use of CT scans in the evaluation of trauma. A hypodense image within an EDH associated with a basal skull fracture, or a hypodense nodule with strong and homogeneous enhancement may raise the suspicion of a pseudoaneurysm. ${ }^{31}$

Although there is no justification to perform routine cerebral angiograms, neurosurgeons should be aware of possible pseudoaneurysms developing late in the context of skull fractures crossing the MMA. One may consider 3D CT angiography in selected cases. ${ }^{21,31}$ Suspect lesions should be confirmed with angiography, followed by treatment with embolization. We don't see any reason to postpone treatment waiting for spontaneous resolution ${ }^{26}$ in the context of an MMA pseudoaneurysm. Interestingly, the first reports of MMA embolization related to traumatic lesions concern the treatment of refractory chronic SDHs. ${ }^{10,16,29}$

The first published series of endovascular treatment of acute EDH was described by Suzuki et al. in 2004; they reported successful embolization in 9 patients with EDHs and associated lesions. ${ }^{28}$ The EDHs were followed conservatively without surgical intervention, and eventually disappeared within an average of 18 days. Surgical intervention was performed in 3 patients with other lesions (contusions and SDHs). As noted by Ross, ${ }^{24}$ this first study was published in a radiological journal. This and the fact that anticoagulation was used in interventional procedures in the setting of TBI are perhaps the reasons for the lack of attention to the endovascular approach.

Misaki et al. ${ }^{17}$ described a case of a 44-year-old woman with intractable otorrhagia and coexisting EDH. The treatment was aimed at the ear bleeding, but stabilization and further resolution of the EDH was observed on serial CT scans. Ross ${ }^{24}$ treated 1 postoperative EDH with MMA embolization. The patient originally had an SDH and developed an EDH (which was drained in a second operation) but rebled and was finally treated successfully with embolization. Ohshima et al. ${ }^{20}$ described the combined treatment of a large EDH with bur hole endoscopic evacuation and MMA embolization in a 74-year-old patient in poor medical condition. Kim et al. ${ }^{13}$ described the usefulness of intraoperative embolization of an MMA pseudoaneurysm for hemostasis as a desperate measure to control acute, life-threatening, uncontrollable bleeding.

De Andrade et al. ${ }^{6}$ described the largest series so far, with 24 patients harboring small EDHs, all associated

TABLE 5. Literature series of 82 patients with acute EDH who initially received conservative management and eventually needed craniotomy

\begin{tabular}{lrrrc}
\hline \multicolumn{1}{c}{ Authors \& Year } & No. of Patients & No. (\%) w/ Shift to Surgical Evacuation & Mean Age (yrs) & EDH Avg Thickness (mm) \\
\hline Knuckey et al., 1989 & 22 & $7(32)$ & 27 & NA \\
\hline Chen et al., 1993 & 74 & $14(19)$ & 24.3 & 15 \\
\hline Sullivan et al., 1999 & 160 & $37(23)$ & 23 & 10 \\
\hline Offner et al., 2006 & 54 & $7(13)$ & 27 & 10.1 \\
\hline Balmer et al., 2006 & 13 & $1(7.7)$ & 9.3 & 19 \\
\hline Jamous et al., 2009 & 6 & $0(0)$ & 11 & 16 \\
\hline Khan et al., 2014 & 17 & $2(11.8)$ & 39.1 & 16 \\
\hline Basamh et al., 2016 & 125 & $14(11.2)$ & 10.2 \\
\hline
\end{tabular}

Avg = average; $N A=$ not available. 

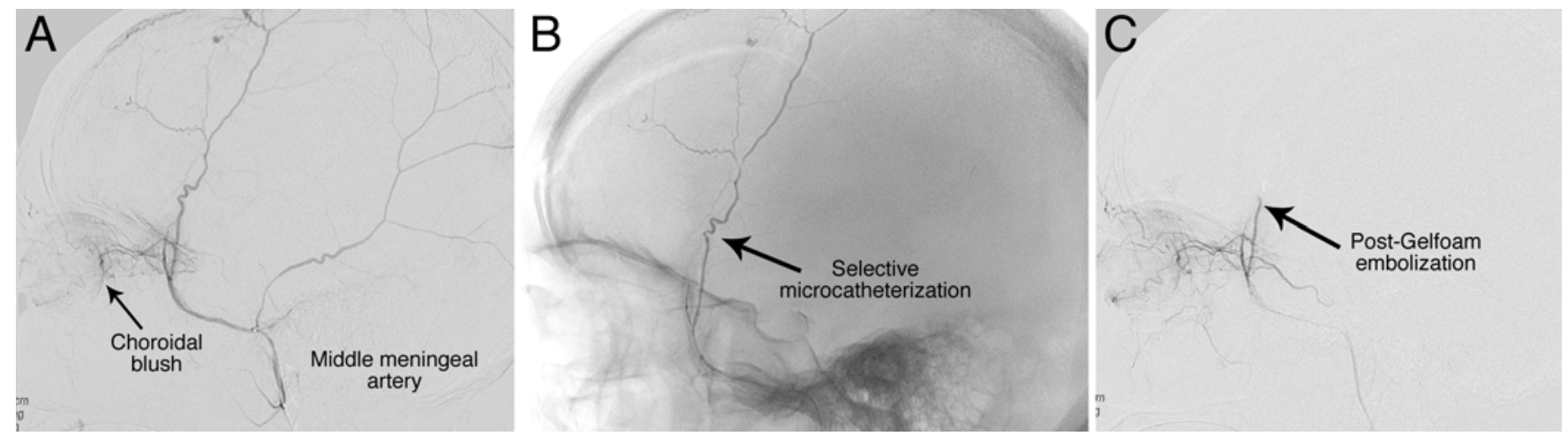

FIG. 5. Superselective MMA angiography showing the choroidal blush and contrast extravasation with pseudoaneurysm distally (A). The microcatheter was gently navigated to a position distal to the anastomosis (B), and safe occlusion of the MMA was performed with gentle Gelfoam injection (no reflux was permitted) (C).

with cranial fractures. They noted active contrast extravasation in $70.9 \%$, pseudoaneurysms in $29.1 \%$, and 2 patients (8.3\%) with AVF.

The embolization procedure, although generally fast and straightforward, must be conducted with extreme caution when dealing with the proximal MMA. In cases in which the meningo-OphA (a remnant of the embryonal stapedial artery) is present, the entire supply to the distal OphA, including the central retinal artery, is the MMA. In this setting, even proximal occlusion of the MMA is dangerous. One may suspect this variation when the OphA is not visualized from the internal carotid artery injection and a choroidal blush is seen on the external carotid artery injection. ${ }^{8}$ In 1 case in our series (Fig. 5), the choroidal blush precluded safe embolization with PVA particles. The strategy in this case was to place the microcatheter as far as possible into the MMA, and the use of Gelfoam as the embolization agent. The final result shows the preservation of the choroidal blush and complete occlusion of the torn distal meningeal artery.

Although we had no control cohort in our study, we performed a review of the literature for historical comparison, and found an incidence of $17.4 \%$ of delayed surgical procedures in 471 patients initially admitted to conservative treatment, compared with no need for surgical evacuation in our series. Given that AVFs were seen in 8 of our 80 cases, another theoretical benefit of the embolization would be the prevention of a rare but possible symptomatic osteodural AVF in the future in these patients.

\section{Limitations of the Study}

This study presents some limitations. First, it does not address the late effects of radiation required to embolize the lesions. However, the radiation required to obtain multiple CT scans in the conservatively managed group may be higher than that in the embolized one. Second, economic issues were not studied. Indeed, health costs are not homogeneous among different countries, and what is costeffective in one country may not be in others. Third, the selection of a historical cohort as a control group may introduce selection and outcome bias, whose effects are difficult to predict and discuss. Publication bias is another issue associated with historical controls from the literature. To better clarify these issues, a randomized trial is under way in our institution to compare these groups of patients directly and to identify differences in the economic issues. Nonetheless, this study has demonstrated that endovascular embolization of MMA and its branches in patients with small EDHs is a simple, safe, and effective procedure to prevent late hematoma expansion.

\section{Conclusions}

Epidural hematomas in patients with cranial fractures that tear dural arteries distal to the foramen spinosum are more prone to develop late rebleeding causing $\mathrm{EDH}$ enlargement. Such intracranial vessel wall injury may cause unstable vascular injuries. This may warrant the embolization of any abnormality found on angiographic studies in these patients, provided that open clot evacuation is unnecessary.

To the best of our knowledge, this is the largest series of endovascular treatment of nonsurgically managed EDHs so far in the literature. It has demonstrated that embolization is safe, with no method-related complications, and highly effective to prevent mortality and morbidity associated with late expansion of small EDHs, when compared with a historical cohort.

\section{References}

1. Balmer B, Boltshauser E, Altermatt S, Gobet R: Conservative management of significant epidural haematomas in children. Childs Nerv Syst 22:363-367, 2006

2. Basamh M, Robert A, Lamoureux J, Saluja RS, Marcoux J: Epidural hematoma treated conservatively: when to expect the worst. Can J Neurol Sci 43:74-81, 2016

3. Bruneau M, Gustin T, Zekhnini K, Gilliard C: Traumatic false aneurysm of the middle meningeal artery causing an intracerebral hemorrhage: case report and literature review. Surg Neurol 57:174-178, 2002

4. Bullock MR, Chesnut R, Ghajar J, Gordon D, Hartl R, Newell DW, et al: Surgical management of acute epidural hematomas. Neurosurgery 58 (3 Suppl):S7-S15, Si-Siv, 2006

5. Chen TY, Wong CW, Chang CN, Lui TN, Cheng WC, Tsai MD, et al: The expectant treatment of "asymptomatic" supratentorial epidural hematomas. Neurosurgery 32:176-179, 1993

6. de Andrade AF, Figueiredo EG, Caldas JG, Paiva WS, De Amorim RLO, Puglia P, et al: Intracranial vascular lesions 
associated with small epidural hematomas. Neurosurgery 62:416-421, 2008

7. de Andrade AF, Marino R, Ciquini O, Figueiredo EG, Machado AG: Guidelines for neurosurgical trauma in Brazil. World J Surg 25:1186-1201, 2001

8. Geibprasert S, Pongpech S, Armstrong D, Krings T: Dangerous extracranial-intracranial anastomoses and supply to the cranial nerves: vessels the neurointerventionalist needs to know. AJNR Am J Neuroradiol 30:1459-1468, 2009

9. Hamilton M, Wallace C: Nonoperative management of acute epidural hematoma diagnosed by CT: the neuroradiologist's role. AJNR Am J Neuroradiol 13:853-862, 1992

10. Hashimoto T, Ohashi T, Watanabe D, Koyama S, Namatame $\mathrm{H}$, Izawa $\mathrm{H}$, et al: Usefulness of embolization of the middle meningeal artery for refractory chronic subdural hematomas. Surg Neurol Int 4:104, 2013

11. Jamous MA, Abdel Aziz H, Al Kaisy F, Eloqayli H, Azab M, Al-Jarrah M: Conservative management of acute epidural hematoma in a pediatric age group. Pediatr Neurosurg 45:181-184, 2009

12. Khan MB, Riaz M, Javed G: Conservative management of significant supratentorial epidural hematomas in pediatric patients. Childs Nerv Syst 30:1249-1253, 2014

13. Kim DH, Lee JY, Jeon HJ, Cho BM, Park SH, Oh SM: Intraoperative endovascular embolization of middle meningeal artery and a pseudoaneurysm by using n-butyl 2-cyanoacrylate for hemostasis during operation of acute epidural hemorrhage. Korean J Neurotrauma 11:167-169, 2015

14. Knuckey NW, Gelbard S, Epstein MH: The management of "asymptomatic" epidural hematomas. A prospective study. J Neurosurg 70:392-396, 1989

15. Lammy S, McConnell R, Kamel M, Rennie I, Al-Haddad S: Extradural haemorrhage: is there a role for endovascular treatment? Br J Neurosurg 27:383-385, 2013

16. Mandai S, Sakurai M, Matsumoto Y: Middle meningeal artery embolization for refractory chronic subdural hematoma. Case report. J Neurosurg 93:686-688, 2000

17. Misaki K, Muramatsu N, Nitta H: Endovascular treatment for traumatic ear bleeding associated with acute epidural hematoma. Neurol Med Chir (Tokyo) 48:208-210, 2008

18. Nayil K, Ramzan A, Makhdoomi R, Wani A, Zargar J, Shaheen F: Incidental traumatic pseudoaneurysm of the middle meningeal artery: case report and literature review. Turk Neurosurg 22:239-241, 2012

19. Offner PJ, Pham B, Hawkes A: Nonoperative management of acute epidural hematomas: a "no-brainer." Am J Surg 192:801-805, 2006

20. Ohshima T, Tajima H, Fujii K, Nagakura M, Nishizawa $\mathrm{T}$, Kato K, et al: Combined endovascular and endoscopic surgery for acute epidural hematoma in a patient with poor health. Neurol Med Chir (Tokyo) 52:829-831, 2012

21. Paiva WS, Andrade AF, Amorim RLOD, Bor-Seng-Shu E, Gattas G, Neville IS, et al: Computed tomography angiography for detection of middle meningeal artery lesions associated with acute epidural hematomas. BioMed Res Int 2014:413916, 2014

22. Paiva WS, de Andrade AF, Amorim RL, Figueiredo EG, Teixeira MJ: Traumatic pseudoaneurysm of the middle meningeal artery causing an intracerebral hemorrhage. Case Rep Med 2010:219572, 2010
23. Protasoni M, Sangiorgi S, Cividini A, Culuvaris GT, Tomei G, Dell'Orbo C, et al: The collagenic architecture of human dura mater. J Neurosurg 114:1723-1730, 2011

24. Ross IB: Embolization of the middle meningeal artery for the treatment of epidural hematoma. J Neurosurg 110:12471249,2009

25. Sakai H, Takagi H, Ohtaka H, Tanabe T, Ohwada T, Yada K: Serial changes in acute extradural hematoma size and associated changes in level of consciousness and intracranial pressure. J Neurosurg 68:566-570, 1988

26. Shah Q, Friedman J, Mamourian A: Spontaneous resolution of traumatic pseudoaneurysm of the middle meningeal artery. AJNR Am J Neuroradiol 26:2530-2532, 2005

27. Sullivan TP, Jarvik JG, Cohen WA: Follow-up of conservatively managed epidural hematomas: implications for timing of repeat CT. AJNR Am J Neuroradiol 20:107-113, 1999

28. Suzuki S, Endo M, Kurata A, Ohmomo T, Oka H, Kitahara $\mathrm{T}$, et al: Efficacy of endovascular surgery for the treatment of acute epidural hematomas. AJNR Am J Neuroradiol 25:1177-1180, 2004

29. Takahashi K, Muraoka K, Sugiura T, Maeda Y, Mandai S, Gohda Y, et al: [Middle meningeal artery embolization for refractory chronic subdural hematoma: 3 case reports.] No Shinkei Geka 30:535-539, 2002 (Jpn)

30. Tsutsumi M, Kazekawa K, Tanaka A, Ueno Y, Nomoto Y, Nii $\mathrm{K}$, et al: Traumatic middle meningeal artery pseudoaneurysm and subsequent fistula formation with the cavernous sinus: case report. Surg Neurol 58:325-328, 2002

31. Wang CH, Lee HC, Cho DY: Traumatic pseudoaneurysm of the middle meningeal artery: possible indicators for early diagnosis in the computed tomography era. Surg Neurol 68:676-682, 2007

32. Wu X, Jin Y, Zhang X: Intraparenchymal hematoma caused by rupture of the traumatic pseudoaneurysm of middle meningeal artery. J Craniofac Surg 25:e111-e113, 2014

\section{Disclosures}

The authors report no conflict of interest concerning the materials or methods used in this study or the findings specified in this paper.

\section{Author Contributions}

Conception and design: Peres, Caldas. Acquisition of data: Peres, Caldas, Puglia, da Silva. Analysis and interpretation of data: Peres, Caldas, Figueiredo. Drafting the article: Peres, Figueiredo. Critically revising the article: Caldas, Puglia, Figueiredo. Reviewed submitted version of manuscript: Peres, de Andrade. Approved the final version of the manuscript on behalf of all authors: Peres. Statistical analysis: Peres. Administrative/technical/material support: Caldas, de Andrade, Teixeira. Study supervision: Caldas, de Andrade, Teixeira, Figueiredo.

\section{Correspondence}

Carlos Michel A. Peres, Hospital Universitário Francisca Mendes, 1085 Av. Via Lactea, Manaus, AM 69060085, Brazil. email: cmaperes@usp.br. 